\title{
Social Justice: School Administrative Staff Perceptions of Strengths, Challenges, and Training Needs in Section 504-Only Services
}

\author{
Dora D. Rodriguez \\ Mercedes ISD \\ Velma D. Menchaca \\ University of Texas Rio Grande Valley \\ George Padilla \\ University of Texas Rio Grande Valley
}

The unfunded mandate of Section 504 presents a challenge to K-12 public schools. A mixed methods design study was completed in schools in South Texas to access school administrative staff perceptions of strengths and challenges in Section 504-Only services and identify needed training and differences between elementary and secondary schools. Top concerns and needed training were identified. No statistical differences were found between elementary and secondary schools among the concerns. State and school administrators need to address concerns and provide needed training to school staff implementing Section 504 to support social justice in schools.

Keywords: Section 504, Americans with Disabilities Act, social justice, school administrators, training

\section{INTRODUCTION}

Legal compliance with Section 504 of the Rehabilitation Act of 1973 to assure non-discrimination and equal opportunity for all students in public schools can overwhelm school administrators. They become overburdened as they participate in decision-making procedures for students with disabilities who require support services (Pazey \& Cole, 2012). Yet, to support social justice through education, school leaders must advocate for students with disabilities.

Recent research is only beginning to uncover some of the challenges and conflicts school administrators are confronted with when they engage in social justice work in our school systems (DeMatthews \& Mawhinney, 2014). In pursuit of social justice, school districts and school district administrators must develop and implement processes that assure a free and appropriate public education (FAPE) to all students. Current laws that support FAPE and govern non-discrimination for students with disabilities in our public schools are Section 504 of the Rehabilitation of 1973, The Americans with Disabilities Act of 1990 and The Individuals with Disabilities Education Act of 2007. There is a very limited amount of research available that addresses the perceptions of stakeholders involved in the Section 504 process (Chiasson \& Olson, 2007). This study primarily addressed the existing literature and research on Section 504 of the 
Rehabilitation Act of 1973 and attempts to identify and assess the perceptions of school administrative staff regarding current strengths and challenges in overseeing the implementation Section 504-Only services and identifying needed training in our public-school systems.

\section{SOCIAL JUSTICE}

Social justice is the belief that all people, irrespective of belief, and societal position, are entitled to be treated according to the values of human rights, human dignity, and equality. It is an act of fairness, equality, and justness towards others (Potgieter et al., 2015). Plato considered education as a means to achieve both individual justice and social justice. He believed individual justice could be obtained when each develops his or her ability to the fullest. He also believed virtue could be achieved through three stages of development of knowledge: knowledge of one's job, self-knowledge, and knowledge of the Idea of the Good. Plato believed that all people could easily exist in harmony when society gives them equal educational opportunity from an early age to compete fairly with each other (Friere, 1970). Plato's philosophical views serve as a framework of current federal laws that apply to public education and nondiscriminatory practices in education.

More currently, Rawls' theory of justice emphasizes fairness of opportunity with the provision of the greatest benefit to the least advantaged in society; this includes youths in schools (Cornelius \& Harrington, 2014). Social justice is described as the belief that all people, irrespective of belief and societal position, are entitled to be treated according to the values of human rights, human dignity, and equality. It is an act of fairness, equality, and justness towards others (Potgieter, et al., 2015). Theoharis (2007, p. 222) describes the literature as "rife" with definitions of social justice. Theoharis $(2007,223)$ also defines social justice as "addressing and eliminating marginalization in schools". John Rawls also theorizes that a well-ordered society is governed by the relational conduct of individuals who can make judgments on what is right versus what is good. This is done by decision-making processes that consist of value-based conduct that benefits both the student and the school community (Potgieter et al., 2015).

\section{Social Justice in Schools}

Decision making is critical in all areas of society. This is particularly true for schools because a child's education can determine his economic and social future (Snyder et al., 2019). In schools, social justice promotes that every student should have an opportunity to achieve his or her fullest capability. Gorski (2013) advised educators should strive to be equitable by recognizing individual differences and adjust the allocation of resources accordingly. He noted people with disabilities face inequities that limit their opportunities. According to DeMatthews and Mawhinney (2014), scholars have long argued that students with disabilities have been marginalized concerning access to curriculum, peers, teachers, and social standing within public schools. Research has shown rates of employment and poverty among people with disabilities, and especially among people with two or more disabilities are among the highest of any identity group (Stapleton, et al., 2006, as cited in Gorksi, 2013). These social facts loudly proclaim the social injustice that exists involving people with disabilities

The issue of social justice is alive and well in America, especially for students with disabilities in public schools. Federal and state laws exist and will continue to exist to ensure social justice in schools (U.S. Department of Education, 2016). While these laws are necessary to provide legal support and directives, real social justice happens in the midst of schools and student experiences. At the school level, while teachers may be the "key" to improving the experience of students with disabilities in the classroom (Bunch et al., 2011, p. 5), principals are critical in supporting, guiding, and leading all keys in a school to advocate for all students and ensure social justice (Howard, 2006). At the school level, significant legislative changes and challenges can create huge hurdles in understanding and implementing successful learning for all students. Federal law Section 504 is critical to social justice for students with learning challenges. This law is highly complex in its requirements, has become a major responsibility of school principals and staff, and if implemented improperly, can cause schools to lose federal funding (ADAAA of 2008). As important as social justice is for children with disabilities and federal funding for schools, it is imperative to assess and 
meet the needs of school principals and staff who implement Section 504. To do less is to undermine the intent of the laws and social justice. This study is designed to identify and assess current strengths and challenges in overseeing the implementation of the Section 504-Only services as perceived by practicing elementary and secondary school administrative staff in Texas schools. This research focuses on the study of the schools' Section 504-Only services conditions, training, and identifying differences between elementary and secondary schools in these areas.

\section{Federal Laws Supporting Social Justice in Schools}

Three major federal laws that advocate for social justice for people with disabilities, including students in schools, are: Section 504 of the Rehabilitation Act of 1973, Individuals with Disabilities Education Act (IDEA), American Disabilities Act (ADA), and American Disabilities Amendment Act of 2008 (ADAAA). To understand social justice efforts in the learning of students with disabilities in schools, it is important to understand how these laws relate to each other.

Section 504 of the Rehabilitation Act of 1973 (Section 504) is a civil rights law that protects the rights of individuals with disabilities in programs and activities, public and private, that receive federal financial assistance. Section 504 states:

"No otherwise qualified individual with a disability in the United States . . . shall, solely by reason of her or his disability, be excluded from the participation in, be denied the benefits of, or be subjected to discrimination under any program or activity receiving Federal financial assistance ...." (Nondiscrimination under Federal grants and programs, 1973).

Section 504 provides no extra funding for schools (Kline et al., 2017). To meet the legal requirements of Section 504, schools must remove barriers to learning for students with disabilities.

Individuals with Disabilities Education Act (IDEA) was passed in 1975 as the Education for All Handicapped Children Act. IDEA states:

Disability is a natural part of the human experience and in no way diminishes the right of individuals to participate in or contribute to society. Improving educational results for children with disabilities is an essential element of our national policy of ensuring equality of opportunity, full participation, independent living, and economic self-sufficiency for individuals with disabilities. (Individuals with Disabilities Education Act. (Individuals with Disabilities Education Improvement Act of 2004)

The intent of IDEA is to provide a free appropriate public education (FAPE) to children who have disabilities in at least one of the 13 categories in the law and who need special education to make progress in school. IDEA gives parents or legal guardians a voice in their child's education. IDEA focuses on youths from birth through high school graduation or age 21 if high school graduation has not been achieved. IDEA allocates federal funds to schools to provide special education and related services to eligible children with disabilities (Bowman, 2011).

The American with Disabilities Act (ADA) is a civil rights law originally passed by Congress in 1990 . ADA states:

the Nation's proper goals regarding individuals with disabilities are to assure equality of opportunity, full participation, independent living, and economic self-sufficiency for such individuals (Americans with Disabilities Act, 1990).

ADA (1990) protects individuals with disabilities from discrimination in the workplace, as well as schools and other settings. In 2008, the United States Congress passed into law the Americans with Disabilities Act Amendment Act (ADAAA). This law was enacted to restore the intent and protections of the original ADA 
after a series of Supreme Court decisions that Congress viewed as a very narrow interpretation of the ADA (Kiviniemi \& Sanjo, 2012). ADAAA states:

Congress recognized that physical and mental disabilities in no way diminish a person's right to fully participate in all aspects of society, but that people with physical or mental disabilities are frequently precluded from doing so because of prejudice, antiquated attitudes, or the failure to remove societal and institutional barriers (Americans with Disabilities Act Amendment Act of 2008, As Amended, p. 5)

ADAAA significantly reversed prior judicial interpretations of the definition of an "individual with a disability" under the Americans with Disabilities Act and its sister statute, Section 504 of the Rehabilitation Act of 1973 (Zirkel, 2009c). Essentially, ADAAA lowered the threshold for what constitutes standards regarding substantial limitations to a major life activity. It clarified the effects of mitigating measures and why they should not be considered when determining the degree to which a disability impacts a major life activity. ADAAA also expanded the list of major life activities to include reading, thinking, and concentrating (Kiviniemi \& Sanjo, 2012). ADAAA vastly influences public schools because it broadened the interpretation of ADA and expanded the eligibility criteria for civil rights protection (Cortiella \& Kaloi, 2010).

As parallel laws, the expanded coverage of ADAAA applies to Section 504. More students with disabilities are now entitled to protection from discrimination based on their disabilities and eligible to receive special education or general education with related services and reasonable accommodations under Section 504 (Bowman, 2011; Cortiella, 2011; Cortiella \& Kaloi, 2010). So, before ADAAA, students who were determined by a multidisciplinary team to possess one or more of 13 specific disability categories received Section 504 protection under IDEA through special education services. ADAAA identified additional students with disabilities that did not qualify under IDEA's 13 specific disability categories.

Thus, Section 504 includes students with a physical or mental impairment that substantially limits one or more major life activities, has a record of such impairment, or is regarded as having such impairment. Life activities include walking, seeing, hearing, speaking, breathing, learning, working, caring for oneself, and performing manual tasks even if the student has learned to overcome the impairment and is not experiencing learning difficulties. Section 504 includes students with disabilities eligible for IDEA and students with disabilities not eligible for IDEA. Section 504 students not eligible for IDEA are identified as "504-Only" students (Weathers \& Zirkel, 2016). Schools must address these students with disabilities added by ADAAA under Section 504, so they receive an education comparable to that provided to students without disabilities (U.S. Department of Education Office of Civil Rights, 2018). School districts have been adjusting to the effects of the ADAAA 2008 (Zirkel, 2009a) and its impact on public schools, especially since federal funding is not provided to address 504-Only students (Weathers \& Zirkel, 2015).

\section{Research On 504-Only Students}

Although there is a lack of research on 504-Only students, a recent study by Weathers and Zirkel (2015) found a nationwide increase in the numbers of students accessing supports under Section 504 protection from $1.02 \%$ to $1.48 \%$ between the academic school years 2009-2010 and 2011-2012. A more recent national estimate completed by Civil Rights Data Collection in 2013-2014 found wide variability in the percentage of 504-Only students reported by schools, (Kline et al., 2017). Some districts across the nation reported the doubling of numbers of students identified as eligible for Section 504-Only services over the last few years, and the demands on the administration to process the written accommodation plans also increased (Kline et al., 2017). High increases in designating 504 students in and striking differences among schools found by Kline's study suggest possible confusion regarding Section 504 eligibility.

In Texas, research shows the number of students identified as Special Education (IDEA) eligible has gradually declined in the last ten years, while the general population of students enrolled in the state's school districts has increased (Texas Education Agency [TEA], 2016). Additionally, across Texas, districts have reported an increase in requests for Section 504 evaluations (Kline et al., 2017). Weathers and Zirkel 
(2015) also reported significant differences among percentages of 504-Only students across race, gender, and Title 1 schools. They found a higher percentage of students designated as 504-Only among White students than minority students, among male students than female students, and among students in nonTitle 1 schools than in Title 1 schools. Weathers and Zirkel suggested Section 504 may include "insufficiently nuanced identification practices" (2015, p. 73).

With the increase in Section 504 students, it is important to understand more specifically what this federal mandate requires. Local education agencies must set forth processes and procedures by which students with disabilities requiring accommodations, services, and supports are identified and evaluated by a group of knowledgeable individuals comprising a Section 504 committee who develops an individual Section 504 service plan. This ensures these students are provided with equal opportunity and a free and appropriate public education, or FAPE, despite physical or mental impairments that impact and substantially limit major life activities such as breathing, learning, concentration, reading, thinking, walking, etc. (U.S. Department of Education Office of Civil Rights, 2018). Section 504 decisions must adhere to procedures governing educational setting decisions, evaluation procedures, placement options, and procedural safeguards (U.S. Department of Education Office of Civil Rights, 2016). The parents of children receiving Section 504 services are provided with procedural protections, such as being provided notice and a right to due process (Richards, 2017). As encouraged by the Office of Civil Rights (2016), a Section 504 plan is written by schools to document procedures for identifying and addressing the needs of students with disabilities and to communicate to school personnel the information needed for its implementation (U.S. Department of Education Office of Civil Rights, 2016, p. 10). Section 504 has increased the demands and tasks required for 504-Only students in local education agencies, such as planning meetings, staffing, utilizing increased financial resources, human resources and documentation preparation time (Kline et al., 2017).

Unfortunately, Capper and Young (2014) explain that laws focused on social justice include a lack of coherence in policy and practice and poor fluency among practicing educators who must enforce policies and follow practices. These limitations in federal and state policies make it challenging for educators attempting to meet the needs of their schools (Capper \& Young). School leaders are expected to implement social justice practices by raising student learner outcomes standards, promoting structural reform in their schools, building human resource capacity in their schools, and strengthening their school culture in manners that support students that are traditionally marginalized such as individuals with disabilities (Scanlon \& Theoharis, 2014). School administrators must not only understand the legal requirements of Section 504, but they must understand disability law and how Section 504 services will influence their programs, decisions, facilities, and budgets (Trevino, 2001).

\section{Section 504-Only Student Legal Requirements}

Unfortunately, in the case of Section 504-Only students, school leaders may receive little to no guidance in Section 504 interpretation and application to help meet the instructional and environmental needs of these students (Pazey \& Cole, 2012). While creating socially-just school environments is the responsibility of the campus administrators, other staff members, school teams, and community members are also involved in assuring social justice for all students (Capper \& Young, 2014). Therefore, the lack of procedural coherence and fluency in schools touches many, not just the school administrator.

The preparedness of public school administrators in disability awareness and the availability of professional development regarding decision-making procedures when addressing issues of serving students with disabilities with Section 504 individual accommodations plans (IAPs) should be of great concern. At a time when the most recent trend in educational leadership is social justice, Pazey and Cole (2012) note an overly concerning absence of training in Section 504. Additionally, with limited accessibility to human and financial resources, already difficult problems become even more complicated when busy school administrators must participate in Section 504 decision-making procedures. Moreover, very little consistent guidance and no financial support are provided to schools by school districts. To be fair, school districts are not provided procedures for the implementation of Section 504 services by the federal or state levels and must develop their own procedures. 
Research shows that elementary and secondary level public school administrators are the driving force in creating organizational change for school improvement and more equitable school practices (Scanlan \& Theoharis, 2014). A recent report cited a survey conducted in five surrounding school districts near Carroll County Public Schools (Maryland) that provided a breakdown of the personnel who were case managing 504-Only students. Results indicated that $43.1 \%$ percent of their principals and assistant principals were acting as case managers for their 504-Only students. The study also showed that $25.1 \%$ were guidance counselors, $20.9 \%$ were others such as academic facilitators and teachers, and $10.9 \%$ were school nurses (Kline et al., 2017). Section 504 demands much time and effort by school principals and many other schoollevel staff without additional funding support, unlike IDEA that provides almost 13 billion dollars each year to provide special education services (Kline et al., 2017).

At a time of economic constriction and change, complying with the unfunded mandates of Section 504 of the Rehabilitation Act and the Americans with Disabilities Act Amendment Act of 2008 presents a challenge to K-12 public schools (Zirkel, 2009b). It becomes critical to understand the strengths and challenges school principals are facing in implementing Section 504 for students with disabilities who do not meet the eligibility criteria for services under the IDEA in order to support social justice for students with disabilities.

\section{METHODS}

This mixed methods study examined how school administrative staff perceived strengths and challenges in overseeing the implementation of Section 504-Only services and training needed. This research also examined the differences between the perceptions of elementary and secondary education administrative staff regarding needed training in the implementation of Section 504-Only services.

This study was guided by two quantitative questions and one qualitative research question.

RQ1: What concerns do school administrators participating in 504 committees perceive about 504 procedures?

RQ2: What areas of training do current school elementary and secondary education administrators in public education setting perceive as most needed in applying district 504 procedures?

RQ3: Is there a difference between elementary and secondary level school administrators participating in 504 committees in their perceptions of strengths and challenges (perceptions of concerns, training needs, and utilization of student services) related to the Section 504 decision-making process?

The method selected for this study involved a transformative convergent parallel mixed methods design (Creswell, 2013) based on data gathered from a cross-sectional survey that included a sample of participants from five school districts. These school districts were randomly selected through convenience sampling from medium to large school districts in a nearby, large geographic region in south Texas. Superintendents from each participating school district gave written permission to conduct the study. Schools from each district could choose to participate or not. In this design, the researchers combined quantitative and qualitative data to provide a comprehensive analysis of the research problem (Creswell, 2013). The participants included district supervisors, campus principals, assistant principals, and campus counselors serving as campus administrative support staff.

\section{Sample Participants}

Campus administrators and campus administrative designees serving on Section 504 committees from the five school districts in one Texas regional area were provided access to an online survey for completion that included one pilot study school district. The participating school districts were identified through convenience sampling based on location. Two of the districts were of student populations larger than 20,000 and three were of student populations of fewer than 1,000. The survey included open-ended questions to 
identify and triangulate themes and patterns to question responses that aided in increasing confidence in the reliability of this study. The pilot survey was conducted with a school district of a population of more than 20,000 students to aid in the identification of themes for the final data collection survey. It also helped in the design of a more reliable survey by identifying whether participants understood the directions that were provided for completion of the survey, and how much time it took each participant to complete the survey (Fink, 2013). A pilot survey also helps identify questions that may not be suited for the study. The pilot study results yielded no confusion regarding survey directions or question intent. The pilot study results supported the use of the questionnaire in its initial derived state, with the exception of two questions deleted in order to avoid redundancy.

Descriptive and inferential statistics formed the basis of the analysis of the survey as the researchers intended to examine frequency distributions (numbers and percentages), summaries about the sample, and responses to the survey questions (Fink, 2013). Measures of central tendencies and measures of variations were also calculated. Use of this methodology supported the enhancement and furtherance of human rights and social justice from an ethical stance (Mertens, 2012).

\section{Survey Instrument}

The selected survey instrument used to collect data from the participants was an adaptation of Section 504 School-Based Administrator Survey Blueprint (Maydosz, 2009). Permission was granted from the developer to adapt and administer the survey for this study. The survey focused on "the state of implementation and understanding of Section 504 in the Commonwealth of Virginia's elementary and secondary schools" (Maysosz, 2009, p. 40). The focus of this study was to identify the perceptions of elementary and secondary level public school administrative staff overseeing implementation of the Section 504-Only services more than ten years after Maydosz's study. In particular, this study focused on Section 504 procedures and training. While both studies focused on elementary and secondary schools, this study's geographic focus of South Texas is very different than Maydosz's geographic focus. Therefore, adaptations were made to the Mayzdosz's survey that involved removing questions strictly related to understanding of Section 504 and student demographics since this study's schools' demographics included approximately 97.4\% Hispanic students (TEA, 2016), adding questions related to Section 504-Only services, and also adding open-ended questions in order to expand on strengths and challenges identified by the participants regarding 504-Only students.

The benefits of selecting a survey design administered in an online format included rapid turnaround, efficiency, and availability of the data results (Creswell, 2013). A survey also allowed for strict confidentiality of the research participants, a quick collection of responses and limited researcher influence (Creswell, 2013; Fink, 2013).

Finally, data collection consisted of collecting completed surveys from administrators and administrator designees of two large and three small school districts who participate in or are informed on the Section 504 decision-making process for their respective districts in a state education regional area in South Texas. Strict confidentiality of the individual participants was maintained through the collection and reporting of the data.

\section{RESULTS}

Data was collected from 46 campuses in five school districts in South Texas - two large and three small districts, selected through convenience sampling based on geographic location. School districts in Hidalgo, a South Texas county, were identified by student enrollment size. Five were randomly selected and permission to conduct the study was requested and received from the school district superintendents. All regular schools in the five districts were invited to participate, stratified by school level-elementary or secondary. Of the 83 campuses among the five districts invited to participate, only 46 participated (55.4\%). Of the 156 potential participants, $66(42.3 \%)$ completed the online survey. The low participation rate may have been due to recent changes in data reporting to the Texas Education Agency regarding Section 504 and uncertainty in local confidence of program organization and support by campus leadership (Senate Bill 
1153, 2017). Additionally, U.S. Department of Education Office of Special Education Programs (OSEP) cited Texas Education Agency with problems related to professional development, Child Find, and Free and Appropriate Public Education (TEA, 2018). This issue created much concern in many Texas public educational leaders. Finally, some potential participants identified by school district administration may no longer have had Section 504 responsibilities.

Among the 66 participants, $30(45.5 \%)$ were campus counselors, $17(25.8 \%)$ were campus principals, and $15(22.7 \%)$ were campus assistant principals. More than half of the responding participants, $34(51.5 \%)$, were from elementary level campuses while $30(45.5 \%)$ were from secondary level campuses and two (3\%) were from district level staff. Of the 66 participants, 29 (43\%) participants were from B District, $19(28.8 \%)$ participants were from C District, four (6\%) participants were from D District, nine (13.6\%) were from E District and one $(1.5 \%)$ were from F District. Four participants $(6 \%)$ participated in the survey but did not provide district identifiable information.

\section{Participant Experience and Responsibilities With Section 504}

This section initially presents a description of the study's participants' Section 504 experience and responsibilities and their perceived impact of ADAAA on the number of Section 504 students in their schools. Then, the section focuses on Research Questions 1-2 which include concerns about Section 504 procedures and training needed. Research Question 3 regarding differences between elementary and secondary schools will be integrated throughout the related sections.

In exploring participant experience with Section 504, respondents indicated much experience working with Section 504, with over half (52.3\%) having 11 or more years of experience, one-fifth having five or more years of experience $(20.0 \%)$, and just over one-fourth $(27.7 \%)$ with five or less years of experience. Thus, almost three-fourths of the respondents had five or more years of experience with Section 504 .

Regarding their identified role in Section 504, participants were principal, assistant principal, school counselor, campus 504 coordinator, or other. Almost all campuses (92.1\%) represented in the study included a respondent who self-identified as a Section 504 coordinator. Participants identified their Section 504 primary responsibilities which included, in order of frequency selected: Section 504 Meeting Chairperson (38.5\%) followed by "Other" as specified by the respondent (32.1\%), Case Manager (27.7\%), and Allocating Resources (18.5\%). Additionally, $16.9 \%$ of respondents indicated having more than one primary responsibility — some having all three specific primary responsibilities listed in the question as well as other responsibilities specified by the respondent. Thus, these respondents managed successfully multiple Section 504 responsibilities along with their other primary job responsibilities. In a separate question about the availability of Section 504 forms, all respondents indicated their school districts provided specific forms for Section 504 evaluations, eligibility and plans.

\section{Impact of ADAAA on Number of Section 504 Students}

When asked whether the school had experienced an increase in Section 504 students due to ADAAA, one-half $(50.0 \%)$ of the respondents indicated an increase had occurred. Less than one-third $(31.6 \%)$ did not perceive such an increase, and $18.4 \%$ were unsure whether an increase occurred or not.

\section{Concerns About Section 504 Procedures}

Research Question 1 asks: What concerns do school administrators participating in 504 committees perceive about 504 procedures? The procedures included in the question were: procedural requirements regarding documentation; knowledge of available resources/supports for various categories of disabilities; time constraints for planning and preparing Section 504 meetings, or other. Sixty respondents identified time constraints for planning and preparing for Section 504 meetings as the top area of concern (41.7\%), followed by knowledge of available resources and supports (33.3\%) and procedural requirements (18.3\%). In response to Research Question 3, an independent sample $t$-test to identify significant differences was conducted between secondary and elementary respondents. The $t$-test revealed no statistically significant differences between the mean scores of elementary level participants $(M=2.79)$ and secondary level 
participants $(\mathrm{M}=2.30), t=1.832, p=0.72)$. Thus, the results reflect that elementary and secondary schools had similar concerns with Section 504 procedures.

\section{Section 504 Training}

Regarding Section 504 training, almost two-thirds of the respondents $(62.5 \%)$ had training during the current school year, one-fifth $(20.3 \%)$ had training the previous year, five $(7.81 \%)$ had training three to five years previously, and only two respondents $(3.1 \%)$ had no training, while four $(6.25 \%)$ were unsure when they had training. Almost two-thirds of the respondents (65.0\%) described Section 504 training as "Helpful" or "Very Helpful." Ten (15.6\%) respondents described training as "Somewhat Helpful." Finally, only one respondent (1.6\%) found training "Not Helpful." Schools need to strive to ensure all Section 504 training is "Very Helpful." Of the Section 504 training provided, almost one-half of the respondents indicated the training led by district personnel, $23.4 \%$ by external experts, $17.19 \%$ by Regional Service Center experts, and $6.3 \%$ by campus personnel. Again, a handful of respondents $(6.3 \%)$ indicated receiving no training.

It is positive that $82.8 \%$ of the respondents experienced Section 504 training within about a year-a positive trajectory from Pazey and Cole's (2012) findings of little to no guidance on Section 504. However, the presence of even a few respondents having had no such training, almost one-fifth of those who did receive training not finding it helpful or better, and underutilizing regional services describe a less than perfect condition given the complexity of Section 504 responsibilities. If even one Section 504 staff member receives little to no guidance or training, this could negatively impact the learning and lives of many young students. This would be unacceptable for any parent of such a child, or for any school leader of such a student.

In a 5-point Likert scale question from 1 (Not Comfortable) to 5 (Extremely Comfortable), participants indicated how comfortable they were in making recommendations during Section 504 committee meetings in the areas of Eligibility, Resource Allocation, Related Services, Legal Requirements, Monitoring of 504 Plans, and Accommodations. With a total mean of 3.8 for making recommendations in all the areas combined, results indicated that on the average participants felt less than "Somewhat Comfortable" with making such recommendations in Section 504 committee meetings. They felt most comfortable with recommendations regarding Accommodations $(\mathrm{M}=4.1)$ and least comfortable with Legal Requirements $(\mathrm{M}=3.3)$. For responses to Research Question 3, an analysis for significant differences between elementary and secondary schools was conducted through a two-independent $t$-test. No statistical differences were identified between the mean scores of elementary and secondary schools in any Section 504 meeting recommendation area tested. The results demonstrate that elementary and secondary schools experience no difference in the level of comfort when making various recommendations during Section 504 meetings. However, despite the highest level in comfort making recommendations related to Accommodations, 43 respondents indicated their campuses needed more training on Accommodations (34.9\%) followed by General 504 processes (18.6\%), 504 Basics (9.3\%), 504 Laws (7\%), 504 Plan (7\%), Behavior Supports (4.7\%), and 504 Eligibility, Resource Allocation, Dyslexia, 504 Updates, and 504 Form (2.3\% each).

Research Question 2 asked: What areas of training do current school elementary and secondary education administrators in public education setting perceive as most needed in applying district 504 procedures? Participants were asked in an open-ended question to identify what Section 504 service training they felt they needed. The participant responses to this open-ended question were thematically categorized by two practicing special education trained specialists and one of the researchers, who is also a special education trained specialist. The frequency of the thematic responses was converted to percentages. Consistent with a moderate comfort level in making recommendations in Section 504 meetings, 20\% of the

50 respondents reported they needed more training on Section 504 processes, 16\% on 504 laws, and 12\% on resource allocation.

In summary, data were analyzed from 66 participants serving 43 campuses in South Texas. Areas of strengths and challenges were identified related to Section 504 implementation, strengths, and challenges among elementary and secondary schools. 


\section{DISCUSSION}

The purpose of this study was to examine the perceptions of elementary and secondary education administrative staff who oversee Section 504-Only services regarding strengths and challenges and needed training. This information is critical because of an increase in the number of identified students who are now eligible for Section 504 services due to the ADAAA of 2008 (Cortiella \& Kaloi, 2010). Present concerns have been found regarding the lack of funding for Section 504 services and a need for professional development in schools (Madaus \& Shaw, 2008; Zirkel, 2009b). This research investigated the strengths and challenges faced by school staff overseeing services to 504-Only students and identifying differences between elementary and secondary levels.

Study participants were well-experienced with Section 504. Most managed multiple primary responsibilities related to Section 504, and one-half noted an increase in Section 504 students due to ADAAA. Schools should carefully monitor the number of 504-Only students to ensure possible increases do not overburden Section 504 staff that manage multiple responsibilities for the program and be prepared to add staff as needed to ensure continuous program support and effectiveness. This is especially important given that respondents considered time constraints for planning and preparing for Section 504 meetings as the top concern, with knowledge of available resources and supports and procedural requirements following as the next major concerns. Since no significant differences among the identified concerns were found between elementary and secondary school respondents, these concerns must be addressed by schools at all levels in order to support staff working on Section 504 services. Sufficient time to one's job is critical in any field. Districts and schools should ensure not to assign too many extra duties to Section 504 staff to ensure they can be proficient and efficient in addressing the needs of Section 504 students.

Respondents were mostly provided Section 504 training during the current or prior school year. The training provided was described as helpful or very helpful. However, two respondents indicated having received no training, and one respondent described the training as not helpful. Training was provided mostly by district or campus personnel. External experts provided training more often than the local state regional center. Schools must provide "Very Helpful" training to all Section 504 staff members, without exception and in the areas of needs identified by the participants. To do so, districts should take greater advantage of local state regional centers by continuously assessing their own staff needs, utilizing available training available at these centers, and even collaborating with them to provide specific needed training for their staff.

Overall, respondents felt only "Somewhat Comfortable" in making recommendations in Section 504 committee meetings. They felt most comfortable with recommendations related to Accommodations and the least comfortable in the area of Legal Requirements. No significant differences found between elementary and secondary schools in the comfort levels demonstrates that both levels possess a less than moderate level of comfort in making Section 504 recommendations. This less than "Very Comfortable" feeling in making recommendations further stresses the need for training especially in the areas creating the least comfort-Section 504 processes, laws, and resource allocation. Specifically, study participants reported campuses as a whole needing more training in accommodations and general Section 504 processes.

The need for training was further supported when participants indicated that over one-half of them sought assistance on Section 504 matters 1-4 times during a semester, and over one-quarter sought assistance up to almost weekly. They identified the accommodations as the most sought out area for assistance among eligibility, related services, consultative services, discipline, and dispute resolution. Elementary schools sought more assistance than secondary schools in all six categories and significantly higher in accommodations. Elementary schools also accessed special transportation as a service for students significantly more than secondary schools.

Although this study identified strengths and challenges in meeting the needs of Section 504-Only students as perceived by school administrative staff who oversee implementation of the Section 504-Only services, further research is recommended. First, since this study was limited to Hispanic students in south Texas schools, identifying and comparing the strengths and challenges in different geographic areas of the country and/or for other student ethnic groups would add to the current findings. Second, in identifying 
perceived challenges, it is important to identify solutions or programs that may be available to overcome these challenges. Collaboration and sharing among school districts are critical to help identify successful programs and practices. Third, time constraints were a major challenge for participants in the study. It is critical to specifically assess that challenge and identify processes that help overcome it, such as: a reasonable case load and time-saving practices and procedures. Fourth, it is important to deepen the understanding of identified strengths in order to design aligned programs and then advocate their use so other school systems can learn and apply them. Future research in these areas will greatly improve the educational and life successes of current and future 504-Only students, further supporting social justice.

Schools may have confident and diligent staff working with Section 504, but, most notably, this research has increased the knowledge and understanding of the strengths and challenges as reported by school staff working with 504-Only students. This helps tremendously identify the knowledge and skills that must be improved as reported by Section 504 practicing school staff. School districts strongly commit to include staff development on Section 504 for all school personnel, school improvement teams, child study teams, and especially those working directly with Section 504. Personnel preparation programs have previously focused on prescriptive requirements of the IDEA. Schools and educational preparation programs must overcome identified challenges through more improved specialized training and greater support in order to better prepare school staff that make life-changing decisions for 504-Only students, especially those who are making decisions right now, because waiting wastes children's potential and weakens social justice.

\section{REFERENCES}

Americans with Disabilities Act of 1990, 42 U.S.C. § 12101. (1990).

Americans with Disabilities Act Amendments Act (ADAAA) of 2008, 42 U.S.C.A. $\$ 12101$ note. (2008). Bowman, L. (2011). Americans with disabilities act as amended: principles and practice. New Directions for Adult and Continuing Education, 132, 85-95.

Bunch, G., Al-Salah, R., \& Pearpoint, J. (2011). Equity, social justice, disability and secondary schools: What regular subject teachers can do. Inclusion Press.

Capper, C.A., \& Young, M.D. (2014). Ironies and limitations of educational leadership for social justice educators. Theory Into Practice, 53, 158-164.

Chiasson, K., \& Olson, M.R. (2007). The section 504 process in the middle school: Perspectives of parents, teachers, and section 504 coordinators. Journal of the American Academy of Special Education Professionals, pp. 81-95.

Cornelius, L.J., \& Harrington, D. (2014). A social justice approach to survey design and analysis. Oxford University Press.

Cortiella, C., \& Kaloi, L. (2010). Meet the new and improved section 504. Exceptional Parent, 40(2), 1415.

Cortiella, C. (2011). The state of learning disabilities: Facts, trends, and indicators. New York, NY: National Center for Learning Disabilities. http://www.ld.org

Creswell, J.W. (2013). Research design: qualitative, quantitative, and mixed methods approaches. Sage Publications.

DeMatthews, D., \& Mawhinney, H. (2014). Social justice leadership and inclusion: Exploring challenges in an urban district struggling to address inequities. Educational Administration Quarterly, 50(5). 844-881.

Freire, P. (1970). Pedagogy of the oppressed. Continuum.

Fink, A. (2013). How to conduct surveys. Sage Publications.

Gorski, P.C. (2013). Reaching and teaching students in poverty: strategies for erasing the achievement gap. Teachers College Press.

Howard, G. (2006). We can't teach what we don't know: White teachers, multiracial schools (2nd ed.). Teachers College Press. 
Individuals with Disabilities Education Improvement Act of 2004 (Public Law No.108-446. (2004, December 3). United States House of Representatives Office of the Law Revision Council, United State Codes. Retrieved from https://uscode.house.gov/browse.xhtml

Kiviniemi, J., \& Sanjo, C. (2012). The americans with disabilities act (ADA) provisions and protections (p.1). Nova Science Publishers.

Kline, J.J., Bocchino, L., Herseim, J., Slater, A.E., \& Watson, J. (Eds.). (2017). Increase in Section 504 population strains district resources. Section 504 Compliance Advisor, 21(7), 4-5.

Madaus, J.W., \& Shaw, S.F. (2008). The role of school professionals in implementing section 504 for students with disabilities. Educational Policy, 22(3), 363-378.

Maydosz, A.S. (2009). An examination of section 504 in practice: Dark days for student rights (Publication No. 3393002) [Doctoral dissertation, Old Dominion University]. ProQuest Dissertations and Theses Global. Retrieved from https://www.proquest.com/docview/305069311

Mertens, D. (2012). What comes first? the paradigm or the approach? Journal of Mixed Methods Research, 6(4), 255-257. https://doi:10.1177/1558689812461574

Nondiscrimination under Federal grants and programs, 29 U.S.C. § 794a. (1973). Retrieved from https://uscode.house.gov/view.xhtml?req=granuleid:USC-prelim-title29section794\&num $=0 \&$ edition $=$ prelim

Pazey, B.L., \& Cole, H.A. (2012). The role of special education training in the development of socially just leaders: building an equity consciousness in educational leadership programs. Educational Administration Quarterly, 49(2), 243-271.

Potgieter, F.G., Van Deventer, I., \& Van der Westhuizen, P.C. (2015). Social justice praxis in education: towards sustainable management strategies. South African Journal of Education, 35(2), 1-11. https://doi: 10.15700/saje.v35n2a. 956

Richards, D. (2017, November). A stroll through CESD's 504 forms. Presented at CESD's $21^{\text {st }}$ Annual Southwest Conference, Double Tree Hotel, Austin, TX.

Scanlan, M., \& Theoharis, G. (2014) This issue. Theory into Practice, 53(2), 79-81. https://doi: $10.1080 / 00405841.2014 .885807$

Senate Bill 1153. (2017). Texas $85^{\text {th }}$ Leg., Senate Journal page 4245 (enacted).

Snyder, T.D., de Brey, C., \& Dillow, S.A. (2019, December). Digest of Education Statistics 2018. Washington, DC: National Center for Education Statistics, Institute of Education Sciences, U.S. Department of Education.

Stapleton, D.C., O’Day, B.L., Livermore, I.A., \& Imparato, A.J. (2006). Dismantling the poverty trap: Disability policy for the twenty-first century. Milbank Quarterly, 84(4), 701-732.

Texas Education Agency. (2016). Enrollment in Texas Public Schools 2015-16. Retrieved from https://tea.texas.gov/sites/default/files/enroll_2015-16.pdf

Texas Education Agency. (2018). Special Education Corrective Action Response Requirements and Timelines. Austin, TX: Department of Special Populations in Division of Special Education. Retrieved from https://tea.texas.gov/About_TEA/News_and_Multimedia/Correspondence/TAA_Letters/ACTIO N_REQUIRED_Special_Education_Corrective_Action_Response_Requirements_and_Timeline/

Theoharis, G. (2007). Social justice educational leaders and resistance: Toward a theory of social justice leadership. Educational Administration Quarterly, 43(2), 221-258. https://doi.org/10.1177/0013161X06293717

Trevino, J.E. (2001). Ensuring educational opportunity for students with disabilities: A legal analysis of section 504 of the rehabilitation act of 1973. (Publication No. 3010271) [Doctoral dissertation, The University of Texas-Pan American]. ProQuest Dissertations and Theses Global. Retrieved from http://search.proquest.com/docview/304788648? accountid $=7116$

U.S. Department of Education, Office of Civil Rights. (2016). Parent and educator resource guide to section 504 in public elementary and secondary schools. Retrieved from http://www2.ed.gov/about/offices/list/ocr/index.html 
U.S. Department of Education, Office of Civil Rights. (2018). Protecting students with disabilities. Retrieved from https://www2.ed.gov/about/offices/list/ocr/504faq.html

Weathers, J.M., \& Zirkel, P.A. (2015). Section 504 only students: National incident data. Journal of Disability Policy Studies, 26(3), 184-193. https://doi: 10.1177/1044207314543560

Weathers, J.M., \& Zirkel, P.A. (2016). K-12 students eligible solely under section 504: Updated national incidence data. Journal of Disability Policy Studies, 27(2), 67-75. https://doi: $10.1177 / 1044207315626115$.

Zirkel, P.A. (2009a). What does the law say. Teaching Exceptional Children, 41, 68-71.

Zirkel, P.A. (2009b). History and expansion of section 504 student eligibility: Implications for school nurses. Journal of School Nursing, 25(4), 256-260.

Zirkel, P.A. (2009c). Section 504: Student eligibility update. Clearing House: A Journal of Educational Strategies, Issues and Ideas, 82(5), 209-211. 